\title{
Total Station Survey Monitoring Through an Observation Window: A Systematic Error Correction to Remove the Effects of Glass Properties
}

\author{
Thomas B. Afeni ${ }^{1}$ and Frederick T. Cawood ${ }^{1}$ \\ ${ }^{1}$ School of Mining Engineering, Faculty of Engineering and the Built Environment, \\ University of the Witwatersrand, Johannesburg, South Africa. \\ Email: olubusuyiafeni@gmail.com; frederick.cawood@wits.ac.za
}

http://dx.doi.org/10.4314/sajg.v5i2.3

\begin{abstract}
Total stations are used extensively for taking geodetic and engineering survey measurements. These measurements are made possible by accurate observation of targeted points. One example is deformation surveys, slope stability monitoring, in mines. Continuous monitoring necessitates sheltering or housing the instrument to protect it against harsh weather conditions that are characteristic of mining environments. Previous studies carried out by Afeni and Cawood (2012) revealed that the properties of the glass material matters when using a total station to take observations through a glass window of a structure that houses the total station at a mine. This study briefly discusses total station survey monitoring and developed systematic error correction formula to reduce the effect of glass properties, such as thickness and colour, on distance measurements through a shelter window glass in a surface mine environment. Each developed formula is combined with the atmospheric corrections formula given by Leica Geosystem, who is the manufacturer of the total station used in this research, to form a combined atmospheric and glass correction formula. The formula performed well when tested on two sets of observations.
\end{abstract}

\section{Introduction}

Survey monitoring, be it slope monitoring or structural monitoring for movement, is done to detect movement that could lead to failure and to allow for sufficient warning to successfully evacuate the area or structure. Wyllie and Mah (2004) declared that, "because of the unpredictability of slope behaviour, movement monitoring programmes can be of value in managing slope hazards, and they provide information that is useful for the design of 
remedial work". Slope movement is most common in open-pit mines, and many mines continue to operate safely for years with moving slopes that are carefully monitored to give warning of deteriorating stability conditions. The authors also described other human activities that can be detrimental to slope stability apart from open pit-mines, namely excavations of the base, and changing the ground water conditions by dam filling or irrigation. Total station monitoring survey techniques are common practice in many open-pit mines, in addition to other geodetic and geotechnical instrumentation. It has become the norm to use robotic total stations in a fully and automated way as part of the monitoring systems in mines (Duffy et al., 2001; Leung, 2001).

The use of total station surveying instruments for monitoring structures' movement with good results were reported by many authors including Radovanovic and Teskey (2001), Hill and Sippel (2002), Kuhlmann and Glaser (2002), Zahariadis and Tsakiri (2006), as well as Lange and Kippelen (2008). Continuous monitoring, as an important operation in an openpit mine to ensure the safety and stability of the mine highwall, was described by Palazzo et al., (2006).

Since continuous slope monitoring with a total station requires the machine to be left in the field, this necessitates housing the instrument inside an observation house, or office, as the case may be. Slope monitoring is always carried out through the window of such an observation house. The window is usually covered with glass material. The properties of the window glass, such as thickness and colour, are not always taken into consideration during the selection, installation and actual monitoring process. Even if this impact may be an additive constant, its magnitude needs to be known and adequately catered for during the analysis of the survey monitoring data.

Systematic errors are not revealed by taking the same measurement again with the same instruments or method, such as taking total station distance measurements through an observation window glass. Taylor (1999) expressed that constant systematic errors are very difficult to deal with because their effects are only observable if they can be removed. Such an error cannot be removed by repeating measurements or averaging large numbers of results. The only way to check adequately for systematic error is to re-measure the quantity by an entirely different method, such as taking total station distance measurements without an observation window glass. It must be ensured that measurements are as accurate as required by removing the effects of all factors that, if neglected, would result in significant error. The 
error caused by some factors can be eliminated with the correct observing procedure, and others can be countered by applying appropriate corrections (Bannister et al, 1998).

This study examined the likely impact of the glass properties, namely thickness and colour, on distances measured through it with a total station and provides a possible way of mitigating the impact.

\section{Materials and Method}

The research was carried out to isolate atmospheric corrections formula from glass properties, such as thickness and colour impact on distances measured with total station. This case study examines the likely impact of such observation window glass properties on distance measurement and developed systematic error correction formulae to remove or reduce such impact. A new total station - TCR 1201 - was procured due to its high sensitivity and accuracy specifications by the school of Mining Engineering, University of the Witwatersrand, Johannesburg for a $\mathrm{PhD}$ research project on likely impacts of atmospheric variation when taking observations through a window glass on the accuracy of data generated using total station surveying instruments. The school also procured five (5) clear float glass panes of different thickness, namely $2 \mathrm{~mm}, 3 \mathrm{~mm}, 4 \mathrm{~mm}, 5 \mathrm{~mm}$ and $6.38 \mathrm{~mm}$ respectively, and two (2) tinted $3.0 \mathrm{~mm}$ glass panes that could easily be exchanged in a special window frame as shown in Figure 1 below:

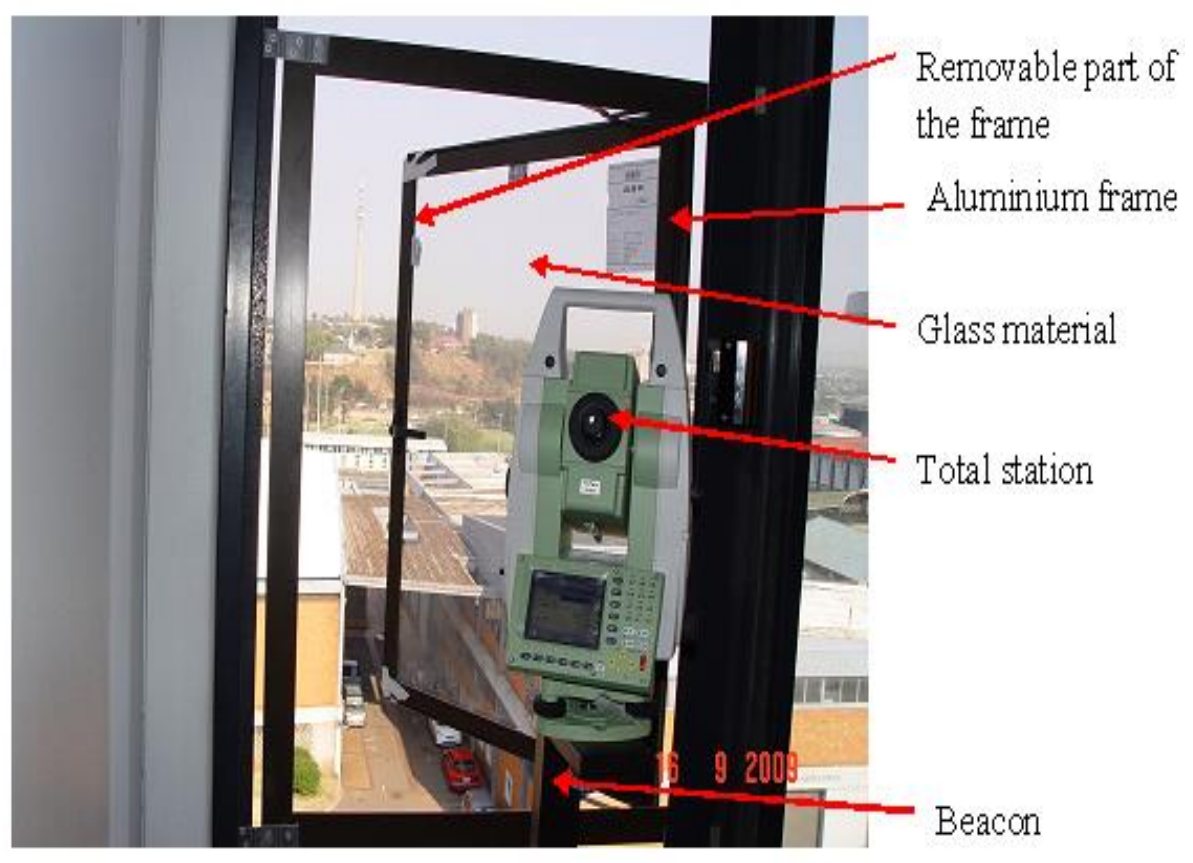

Figure 1: Instrument station set-up showing window frame, total station and beacon 
The detail of materials and methods used to establish the importance of the impact of the glass properties, with regards to thickness and colour on distance measurements through instrument shelter window glass was explained by Afeni and Cawood (2012). The paper established that glass properties have an impact on the measured distances. It also established that the total station manufacturer-proposed atmospheric correction formulae work perfectly to cater for the effects of atmospheric variations on distances measured without glass. The formulae do not in any way remove or reduce the impact caused by the glass material on the distance measurements, because the formulae were not developed for glass impact correction. However, the authors noted that the glass material has little or no impact on vertical distance (VD) measurements and that the impact caused by $2.0 \mathrm{~mm}$ and $3.0 \mathrm{~mm}$ glass on horizontal distance (HD) measurements were within the accuracy limits of $1 \mathrm{~mm}+1.5 \mathrm{ppm}$, when using IR mode, as specified in the instrument manual regardless of different angles intersecting the glass (i.e. when the glass is at different angles to the line-of-sight of the total station). The data generated in Afeni and Cawood (2012) were subjected to linear regression to develop a model for removing the impact caused by the glass properties, such as glass thickness above $3.0 \mathrm{~mm}$ and glass colour - light and dark tinted 3.0mm glass, on HD measurements with total station.

\subsection{Development of Systematic Error Correction Formulae to Cater for the Impact of Glass Properties}

The least squares procedure for fitting a line through a set of ' $n$ ' data points is to ensure that the differences between the observed values and corresponding points on the fitted line is "small" in a overall sense. According to Wackerly et al., (2008), a convenient way to accomplish this, and one that yields estimators with good properties, is to minimise the sum of squares of the vertical deviations from the fitted line, as shown in Figure 2 below:

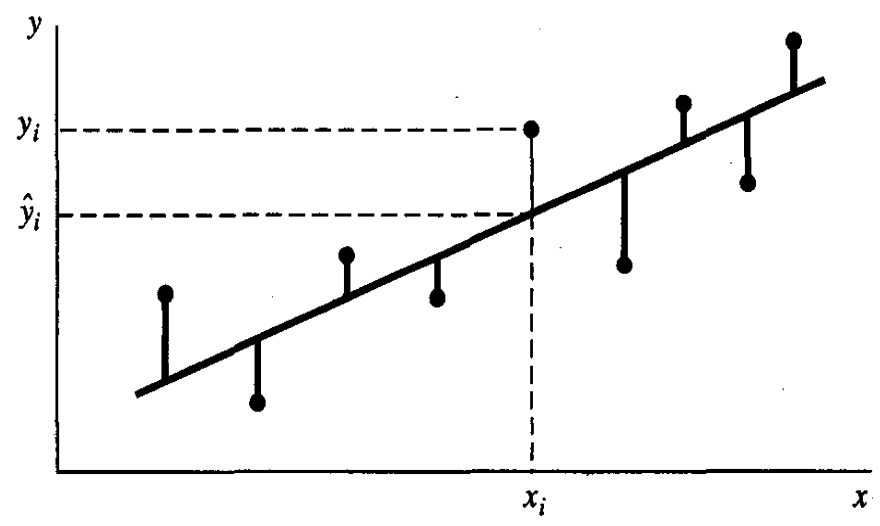

Figure 2: Fitting a straight line through a set of data points (Source: Wackerly et al., 2008) 
Thus, if:

$$
\hat{y}_{i}=b_{0}+b_{1} \hat{x}_{i}
$$

Where:

$\hat{y}$ is the predicted value of the $i$ th y value (when $x=x_{i}$ ), then the deviation, also known as error, of the observed value $y_{i}$ from $\hat{y}_{i}=b_{0}+b_{1} \hat{x}_{i}$ is the difference $y_{i}-\hat{y}_{i}$ and the sum of squares of deviation, also called sum of squares for error, to be minimised is:

$$
S S D=\sum_{i=1}^{n}\left(y_{i}-\hat{y}_{i}\right)^{2}=\sum_{i=1}^{n}\left[y_{i}-\left(\hat{b}_{0}+\hat{b}_{1} x_{i}\right)\right]^{2}
$$

To find the values of $\hat{b}_{0}$ and $\hat{b}_{1}$, which minimise SSD in equation 2; differentiate equation 2 with respect to $\hat{b}_{0}$ and $\hat{b}_{1}$ and set the results equal to 0 :

$$
\begin{aligned}
& \frac{\partial S S D}{\partial b_{0}}=\frac{\left\{\sum_{i=1}^{n}\left[y_{i}-\left(\hat{b}_{0}+\hat{b}_{1} x_{i}\right)\right]^{2}\right\}}{\partial b_{0}}=-\sum_{i=1}^{n} 2\left[y_{i}-\left(\hat{b}_{0}+\hat{b}_{1} x_{i}\right)\right]=-2 \sum_{i=1}^{n}\left(y_{1}-\hat{b}_{0}-\hat{b}_{1} x_{i}\right)=0 \\
& \frac{\partial S S D}{\partial b_{1}}=\frac{\left\{\sum_{i=1}^{n}\left[y_{i}-\left(\hat{b}_{0}+\hat{b}_{1} x_{i}\right)\right]^{2}\right\}}{\partial b_{1}}=-\sum_{i=1}^{n} 2\left[y_{i}-\left(\hat{b}_{0}+\hat{b}_{1} x_{i}\right)\right] x_{i}=-2 \sum_{i=1}^{n}\left(y_{1}-\hat{b}_{0}-\hat{b}_{1} x_{i}\right) x_{i}=0
\end{aligned}
$$

Equations 3 and 4 above are called the least squares equations for estimating the parameters of a line. The least squares equations are linear in $\hat{b}_{0}$ and $\hat{b}_{1}$, hence they can be solved simultaneously. By solving Equations 3 and 4 simultaneously (Rencher and Schaalje, 2007), we have:

$$
\begin{aligned}
& \hat{b}_{1}=\frac{\sum_{i=1}^{n} x_{i} y_{i}-n \bar{y} \bar{x}}{\sum_{i=1}^{n} x_{i}^{2}-n \bar{x}^{2}}=\frac{\sum_{i=1}^{n}\left(x_{i}-\bar{x}\right)\left(y_{i}-\bar{y}\right)}{\sum_{i=1}^{n}\left(x_{i}-\bar{x}\right)^{2}}=\frac{\sum_{i=1}^{n} x_{i} y_{i}-n \bar{y} \bar{x}}{\sum_{i=1}^{n} x_{i}^{2}-n \bar{x}^{2}} \\
& \hat{b}_{0}=\bar{y}-\hat{b}_{1} \bar{x}
\end{aligned}
$$

where:

$x_{i}$ is glass thickness $(\mathrm{mm})$ or glass colour (\% tint);

$y_{i}$ is glass impact $(\mathrm{m})$;

$n$ is number of observation;

$\bar{x}$ is mean of $x_{i}$, and

$\bar{y}$ is mean of $y_{i}$. 
In order to generate the regression equation, the average daily Horizontal Distance (HD) readings to the prism when testing glass thickness impact, as shown in Table 1, and the average daily HD readings to prism when testing glass colour impact, as shown in Table 2, were reduced to average daily HD readings per three days, as shown in Tables 3 and 4. Since the impact of the angular variations on the HD readings were negligible and still within the accuracy limits in all the glass properties and glass angles or position tested as established in Afeni and Cawood (2012). Therefore, all the HD readings were averaged without minding the glass angles. The HD readings without glass are kept constant as shown in Tables 5 and 6 . Tables 5 and 6 show the average changes in HD readings per 3 days.

Table 1: Average daily HD readings to prism

\begin{tabular}{|l|c|r|r|r|r|}
\hline Date & $\begin{array}{l}\text { Glass } \\
\text { thickness } \\
(\mathrm{mm})\end{array}$ & $\begin{array}{l}\text { HD to prism } \\
\text { without glass }\end{array}$ & $\begin{array}{l}\text { HD to prism } \\
\text { with glass } \\
\text { @ } 45^{\circ}\end{array}$ & $\begin{array}{l}\text { HD to prism } \\
\text { with glass @ } \\
60^{\circ}\end{array}$ & $\begin{array}{l}\text { HD to prism } \\
\text { with glass @ } \\
90^{\circ}\end{array}$ \\
\hline $2009 / 10 / 06$ & 2.00 & 626.5415 & 626.5425 & 626.5428 & 626.5427 \\
\hline $2009 / 10 / 07$ & 2.00 & 626.5410 & 626.5419 & 626.5420 & 626.5419 \\
\hline $2009 / 10 / 08$ & 2.00 & 626.5413 & 626.5424 & 626.5425 & 626.5423 \\
\hline $2009 / 10 / 09$ & 3.00 & 626.5410 & 626.5424 & 626.5427 & 626.5425 \\
\hline $2009 / 10 / 10$ & 3.00 & 626.5410 & 626.5428 & 626.5428 & 626.5429 \\
\hline $2009 / 10 / 11$ & 3.00 & 626.5411 & 626.5427 & 626.5429 & 626.5429 \\
\hline $2009 / 10 / 12$ & 4.00 & 626.5415 & 626.5439 & 626.5438 & 626.5436 \\
\hline $2009 / 10 / 13$ & 4.00 & 626.5416 & 626.5439 & 626.5438 & 626.5437 \\
\hline $2009 / 10 / 14$ & 4.00 & 626.5417 & 626.5441 & 626.5440 & 626.5438 \\
\hline $2009 / 10 / 15$ & 5.00 & 626.5413 & 626.5448 & 626.5444 & 626.5442 \\
\hline $2009 / 10 / 16$ & 5.00 & 626.5413 & 626.5447 & 626.5444 & 626.5442 \\
\hline $2009 / 10 / 17$ & 5.00 & 626.5416 & 626.5453 & 626.5451 & 626.5449 \\
\hline $2009 / 10 / 18$ & 6.38 & 626.5417 & 626.5457 & 626.5451 & 626.5450 \\
\hline $2009 / 10 / 19$ & 6.38 & 626.5420 & 626.5460 & 626.5455 & 626.5454 \\
\hline $2009 / 10 / 20$ & 6.38 & 626.5419 & 626.5461 & 626.5452 & 626.5452 \\
\hline
\end{tabular}

Table 2: Average daily HD readings to prism

\begin{tabular}{|l|l|l|l|r|r|r|}
\hline Date & $\begin{array}{l}\text { 3.0mm } \\
\text { Glass } \\
\text { colour } \\
\text { (tinted) }\end{array}$ & $\begin{array}{l}\text { Ave HD } \\
\text { to prism } \\
\text { without } \\
\text { glass }\end{array}$ & $\begin{array}{l}\text { Ave HD } \\
\text { to prism } \\
\text { with glass } \\
\text { @ 30 }\end{array}$ & $\begin{array}{l}\text { Ave HD to } \\
\text { prism with } \\
\text { glass @ 45 }\end{array}$ & $\begin{array}{l}\text { Ave HD to } \\
\text { prism with } \\
\text { glass @ 60 }\end{array}$ & $\begin{array}{l}\text { Ave HD to } \\
\text { prism with } \\
\text { glass @ 90 }\end{array}$ \\
\hline $2010 / 05 / 06$ & Dark & 626.5417 & 626.5449 & 626.5451 & 626.5444 & 626.5441 \\
\hline $2010 / 05 / 07$ & Dark & 626.5417 & 626.5447 & 626.5448 & 626.5443 & 626.5437 \\
\hline $2010 / 05 / 08$ & Dark & 626.5418 & 626.5448 & 626.5451 & 626.5444 & 626.5441 \\
\hline $2010 / 05 / 09$ & Light & 626.5417 & 626.5444 & 626.5441 & 626.5443 & 626.5440 \\
\hline $2010 / 05 / 10$ & Light & 626.5415 & 626.5442 & 626.5438 & 626.5440 & 626.5438 \\
\hline $2010 / 05 / 11$ & Light & 626.5416 & 626.5441 & 626.5442 & 626.5443 & 626.5441 \\
\hline $2010 / 05 / 12$ & Non & 626.5417 & 626.5434 & 626.5433 & 626.5435 & 626.5434 \\
\hline $2010 / 05 / 13$ & Non & 626.5416 & 626.5434 & 626.5433 & 626.5435 & 626.5432 \\
\hline $2010 / 05 / 14$ & Non & 626.5416 & 626.5432 & 626.5433 & 626.5433 & 626.5432 \\
\hline
\end{tabular}


Table 3: Average daily HD readings per 3 days - Glass thickness

\begin{tabular}{|c|c|c|c|}
\hline $\begin{array}{l}\text { Glass thickness } \\
(\mathrm{mm})\end{array}$ & $\begin{array}{l}\text { Average HD } \\
\text { without glass }\end{array}$ & $\begin{array}{l}\text { Average HD with } \\
\text { glass }\end{array}$ & $\begin{array}{l}\text { Difference (glass } \\
\text { impact) }\end{array}$ \\
\hline 2 & 626.5414 & 626.5424 & 0.0010 \\
\hline 3 & 626.5414 & 626.5431 & 0.0017 \\
\hline 4 & 626.5414 & 626.5438 & 0.0024 \\
\hline 5 & 626.5414 & 626.5447 & 0.0033 \\
\hline 6.38 & 626.5414 & 626.5455 & 0.0041 \\
\hline
\end{tabular}

Table 4: Average daily HD readings per 3 days - Glass colour

\begin{tabular}{|l|r|r|r|r|}
\hline Glass colour & $\begin{array}{l}\text { Glass } \\
\text { thickness } \\
(\mathrm{mm})\end{array}$ & $\begin{array}{l}\text { Average HD } \\
\text { without glass }\end{array}$ & $\begin{array}{l}\text { Average HD } \\
\text { with glass }\end{array}$ & $\begin{array}{l}\text { Difference (glass } \\
\text { colour impact) }\end{array}$ \\
\hline None tinted $(0 \%)$ & 3.00 & 626.5416 & 626.5433 & 0.0017 \\
\hline Light tinted $(5 \%)$ & 3.00 & 626.5416 & 626.5441 & 0.0025 \\
\hline Dark tinted $(50 \%)$ & 3.00 & 626.5416 & 626.5445 & 0.0029 \\
\hline
\end{tabular}

Table 5: Average change in HD per glass thickness

\begin{tabular}{|r|r|l|}
\hline Glass thickness & Without glass & With glass (glass thickness impact) \\
\hline 2 & 0 & 0.0010 \\
\hline 3 & 0 & 0.0017 \\
\hline 4 & 0 & 0.0024 \\
\hline 5 & 0 & 0.0033 \\
\hline 6.38 & 0 & 0.0041 \\
\hline
\end{tabular}

Table 6: Average change in HD per glass colour

\begin{tabular}{|c|c|c|}
\hline Glass colour & Without glass & With glass (glass colour impact) \\
\hline Non-tinted & 0 & 0.0017 \\
\hline Light-tinted (5\% tint) & 0 & 0.0025 \\
\hline Dark-tinted (50\% tint) & 0 & 0.0029 \\
\hline
\end{tabular}

Tables 5 and 6 above are used to prepare tables for least squares regression model, as shown in Tables 7 and 8 .

Table 7: Average change in HD per glass thickness for least squares regression model

\begin{tabular}{|l|l|l|l|l|}
\hline S/No & $x_{i}($ Glass thickness, $\mathrm{mm})$ & $y_{i}$ (Glass impact, $\left.\mathrm{m}\right)$ & $x_{i} y_{i}$ & $x_{i}^{2}$ \\
\hline 1 & 2 & 0.0010 & 0.0020 & 4.000 \\
\hline 2 & 3 & 0.0017 & 0.0051 & 9.000 \\
\hline 3 & 4 & 0.0024 & 0.0096 & 16.000 \\
\hline 4 & 5 & 0.0033 & 0.0165 & 25.000 \\
\hline 5 & 6.38 & 0.0041 & 0.02616 & 40.704 \\
\hline Sum & 20.38000 & 0.0125 & 0.05936 & 94.704 \\
\hline Mean & 4.076 & 0.0025 & & \\
\hline
\end{tabular}


Table 8: Average change in HD per glass tint level or colour for least squares regression model

\begin{tabular}{|l|l|l|l|l|}
\hline S/No & $\begin{array}{l}x_{i} \text { (Glass colour, i.e. \% tint } \\
\text { level) }\end{array}$ & $y_{i}$ (Glass impact, m) & $x_{i} y_{i}$ & $x_{i}^{2}$ \\
\hline 1 & 0 & 0.0017 & 0.000 & 0 \\
\hline 2 & 5 & 0.0025 & 0.0125 & 25 \\
\hline 3 & 50 & 0.0029 & 0.1450 & 2500 \\
\hline Sum & 55 & 0.0071 & 0.1575 & 2525 \\
\hline Mean & 27.5 & 0.0024 & & \\
\hline
\end{tabular}

Use Table 7 to substitute for values of parameters in Equations 5 and 6:

$$
\begin{aligned}
& \hat{b}_{1}=\frac{\sum_{i=1}^{n} x_{i} y_{i}-n \overline{y x}}{\sum_{i=1}^{n} x_{i}{ }^{2}-n \bar{x}^{2}}=\frac{0.05936-5(4.076 \times 0.00250)}{94.704-5(4.076)^{2}}=0.00072 \\
& \hat{b}_{0}=\bar{y}-\hat{b}_{1} \bar{x}=0.0025-0.00072(4.076)=-0.0004 \\
& \hat{y}=-0.0004+0.00072 x \\
& \hat{y}_{\text {gtc }}=0.0007 x-0.0004
\end{aligned}
$$

where:

$\hat{y}_{\text {gtc }}$ is the error caused by the glass thickness or glass thickness impact formula. The subscript 'gtc' stands for glass thickness correction:

$x$ is the glass thickness in $\mathrm{mm}$.

Therefore, the combined formula, namely atmospheric and glass thickness corrections will be:

$$
\Delta D_{1}=\left[283.05-\frac{79.7489 P}{(273.15+t)}+\frac{11.27 e}{(273.15+t)}\right] .10^{-6} d^{\prime}-[0.0007 x-0.0004]
$$

Equation 8 above can be expressed as follows:

$$
k^{\prime}=a \cdot 10^{-6} d^{\prime}-\hat{y}_{g}
$$

where:

$\mathrm{k}^{\prime}$ is the correction factor for atmospheric variation and glass thickness effect;

a. $10^{-6}$ is the atmospheric variation correction formula;

$\mathrm{d}^{\prime}$ is the measured distance as it appears on the total station digital screen; and $\hat{y}_{g t c}$ is the glass thickness impact formula. 
Equation 7 is the model for removing the impact of glass thickness, $4.0 \mathrm{~mm}$ and above, on HD readings when using a total station surveying instrument.

Using the same procedure, Table 6 yields:

$$
\begin{aligned}
& \hat{b}_{1}=\frac{\sum_{i=1}^{n} x_{i} y_{i}-n \overline{y x}}{\sum_{i=1}^{n} x_{i}^{2}-n \bar{x}^{2}}=\frac{0.1575-2(27.5 \times 0.0024)}{2525-2(27.5)^{2}}=2 \operatorname{Exp}^{-5} \\
& \hat{b}_{0}=\bar{y}-\hat{b}_{1} \bar{x}=0.0024-2 E^{-5}(27.5)=-0.0020 \\
& \hat{y}_{g c c}=2 \operatorname{Exp}^{-5} x^{\prime}+0.0020 \ldots \ldots \ldots \ldots \ldots \ldots \ldots \ldots \ldots \ldots \ldots \ldots \ldots \ldots \ldots \ldots \ldots \ldots \ldots \ldots \ldots \ldots \ldots
\end{aligned}
$$

where:

$\hat{y}_{g c c}$ is the error caused by the glass colour, m. The subscript "gcc" stands for glass colour correction; and

$x^{\prime}$ is the tint level or colour of the glass (\%).

Therefore, the combined formula for both atmospheric and glass colour corrections will be:

$$
\Delta D_{2}=\left[283.05-\frac{79.7489 P}{(273.15+t)}+\frac{11.27 e}{(273.15+t)}\right] \cdot 10^{-6} d^{\prime}-\left[2 \operatorname{Exp}^{-5} x^{\prime}+0.0020\right]
$$

Equation 11 above can be expressed as follows:

$$
k^{\prime \prime}=a \cdot 10^{-6} d^{\prime}-\hat{y}_{g c}
$$

where:

$\mathrm{k}$ " is the correction factor for atmospheric variation and glass colour effect;

a. $10^{-6}$ is the atmospheric variation correction formula;

$\mathrm{d}^{\prime}$ is the measured distance as it appears on the total station digital screen; and

$\hat{y}_{g c c}$ is the glass colour impact formula.

\subsection{Comparison of the Regression Model Developed with the Physical Model}

The result of the comparison of the regression model developed for glass thickness impact correction with the physical model is presented in appendix A.

\subsection{Observation/Distance Measurement to Test the Model}

In order to test the effectiveness of the systematic error correction formulae developed in the field, two new target stations were chosen to resemble a surface mine environment. The line-of-sight to the two stations passed over a roofing sheet for varying heat generation, a 
football pitch for dust generation and a highway for car exhaust and dust generation in order to simulate a mine environment. Dust, smoke and varying temperature reading are characteristics of mine environments and all these factors were experienced in these new target stations. The first set of HD readings was taken when the target was placed about $468 \mathrm{~m}$ horizontal distance before the target/prism station used to develop the model. The target was later placed beyond the target station used to develop the model, approximately $697 \mathrm{~m}$ in length, to generate the second set of HD readings for validation purposes. During the first set of HD measurements for the model tests, each glass material, namely glass thickness of $4.0 \mathrm{~mm}, 5.0 \mathrm{~mm}$ and $6.38 \mathrm{~mm}$ for the thickness test, and light and dark-tinted glass were used for the glass colour test, was used for two days from 6.00 am to $6.00 \mathrm{pm}$ daily. The data acquired was corrected for prism constant, scale factor and atmospheric corrections. The targets were later moved to the second station, and each glass material was used for only one day as opposed to two days in the first target station. The data acquired was also corrected for prism constant, scale factor and atmospheric corrections. The data was subjected to further analysis and tests to remove the glass impacts on the acquired HD readings.

\section{Results and Discussions}

\subsection{Result and Discussions for Glass Thickness}

The result of the data analysis when monitoring to the Leica circular prism at the first target position during the glass-thickness model test is presented in Figure 3 below. The graph shows the average daily HD measurements corrected for prism constant, scale factor and atmospheric corrections, but not corrected for glass impact. The corresponding result after all corrections, such as the prism constant, scale factor, atmospheric and glass corrections, is presented in Figure 4. 


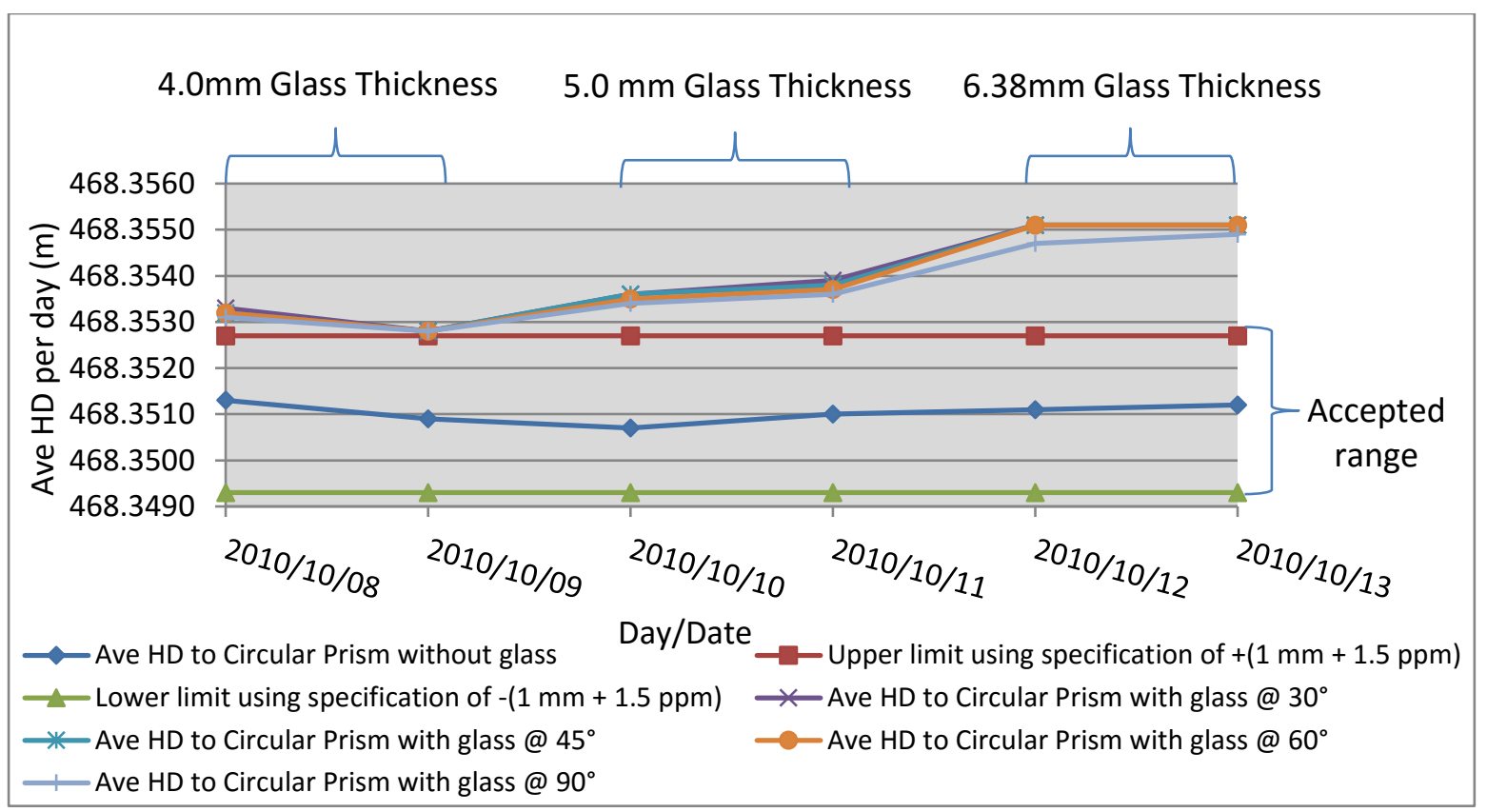

Figure 3: Average HDs to circular prism corrected for prism constant, scale factor and atmospheric corrections, but not corrected for glass thickness impact, as seen in the first target station

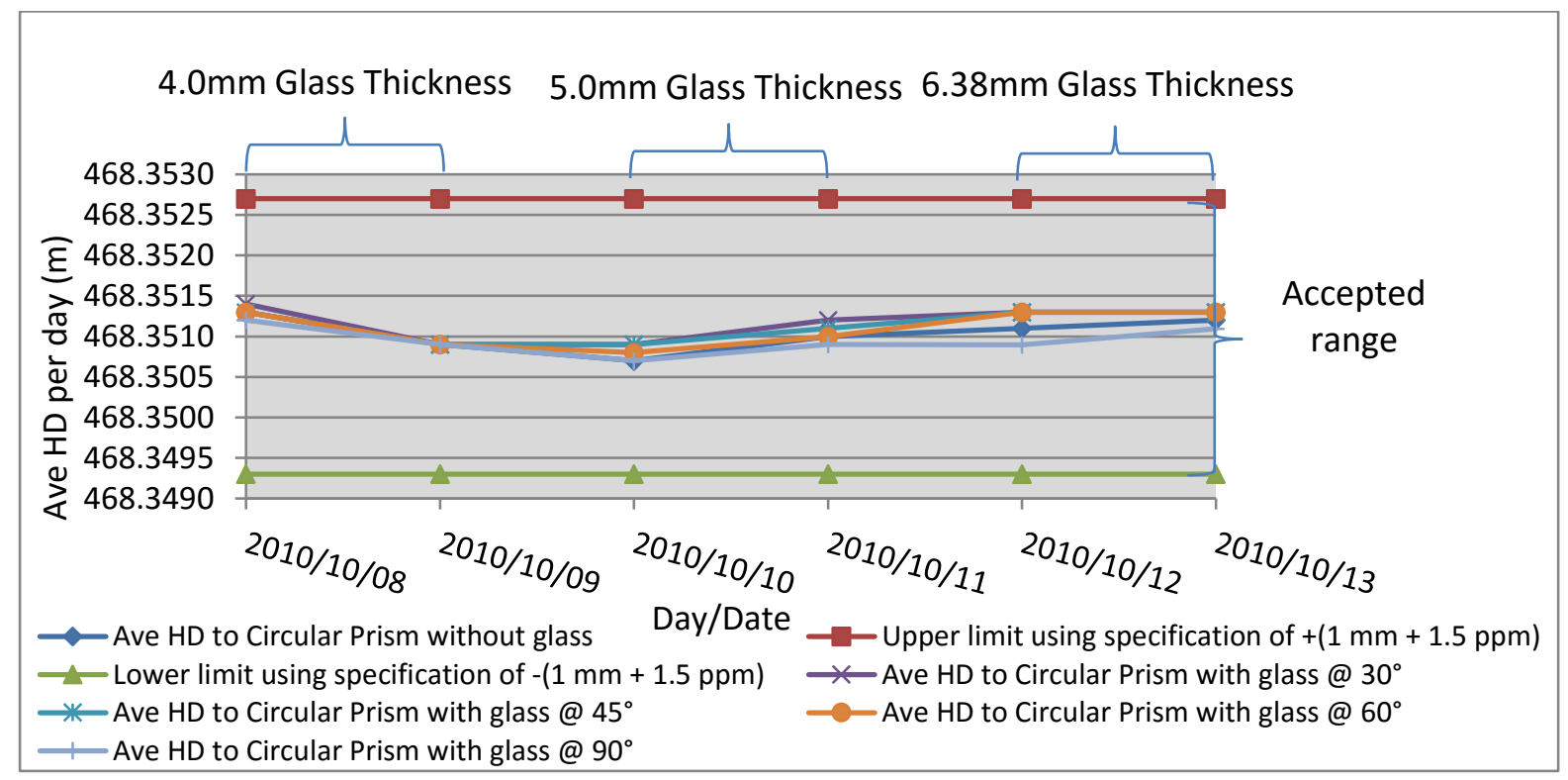

Figure 4: Average HDs to circular prism corrected for prism constant, scale factor, atmospheric and glass thickness, as seen in the first target station

In Figure 3 above, the impact ranged between $1.8 \mathrm{~mm}$ and $2.0 \mathrm{~mm}$ when a $4.0 \mathrm{~mm}$ glass was used. It ranged between $2.6 \mathrm{~mm}$ and $2.9 \mathrm{~mm}$ when a $5.0 \mathrm{~mm}$ glass was used, while a $6.38 \mathrm{~mm}$ glass caused $3.6 \mathrm{~mm}$ and $4.0 \mathrm{~mm}$ impacts. The situation changed after applying the glassthickness correction formula, as demonstrated in Figure 4. The impact range created by a 
$4.0 \mathrm{~mm}$ glass was reduced to $-0.1 \mathrm{~mm}$ and $0.1 \mathrm{~mm}$, a $5.0 \mathrm{~mm}$ glass impact range changed to $-0.1 \mathrm{~mm}$ and $0.2 \mathrm{~mm}$, while a $6.38 \mathrm{~mm}$ glass impact changed to $-0.1 \mathrm{~mm}$ and $0.2 \mathrm{~mm}$ after applying the glass-thickness correction formula to the HDs readings.

The results of the data analysis when monitoring to the Leica circular prism at the second target position are presented in Figures 5 and 6.

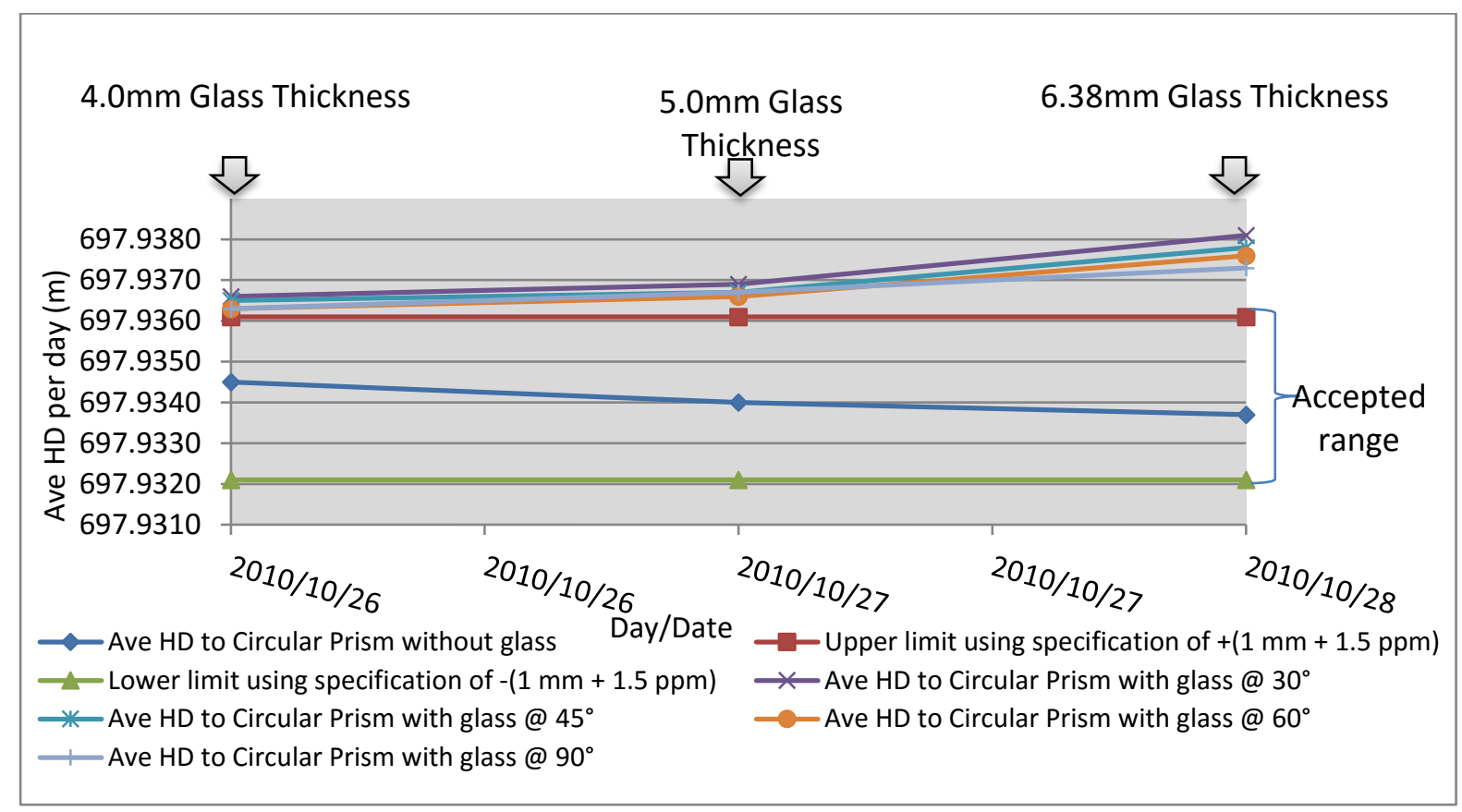

Figure 5: Average HDs to circular prism corrected for prism constant, scale factor and atmospheric corrections, but not corrected for glass thickness impact, as seen in the second target station

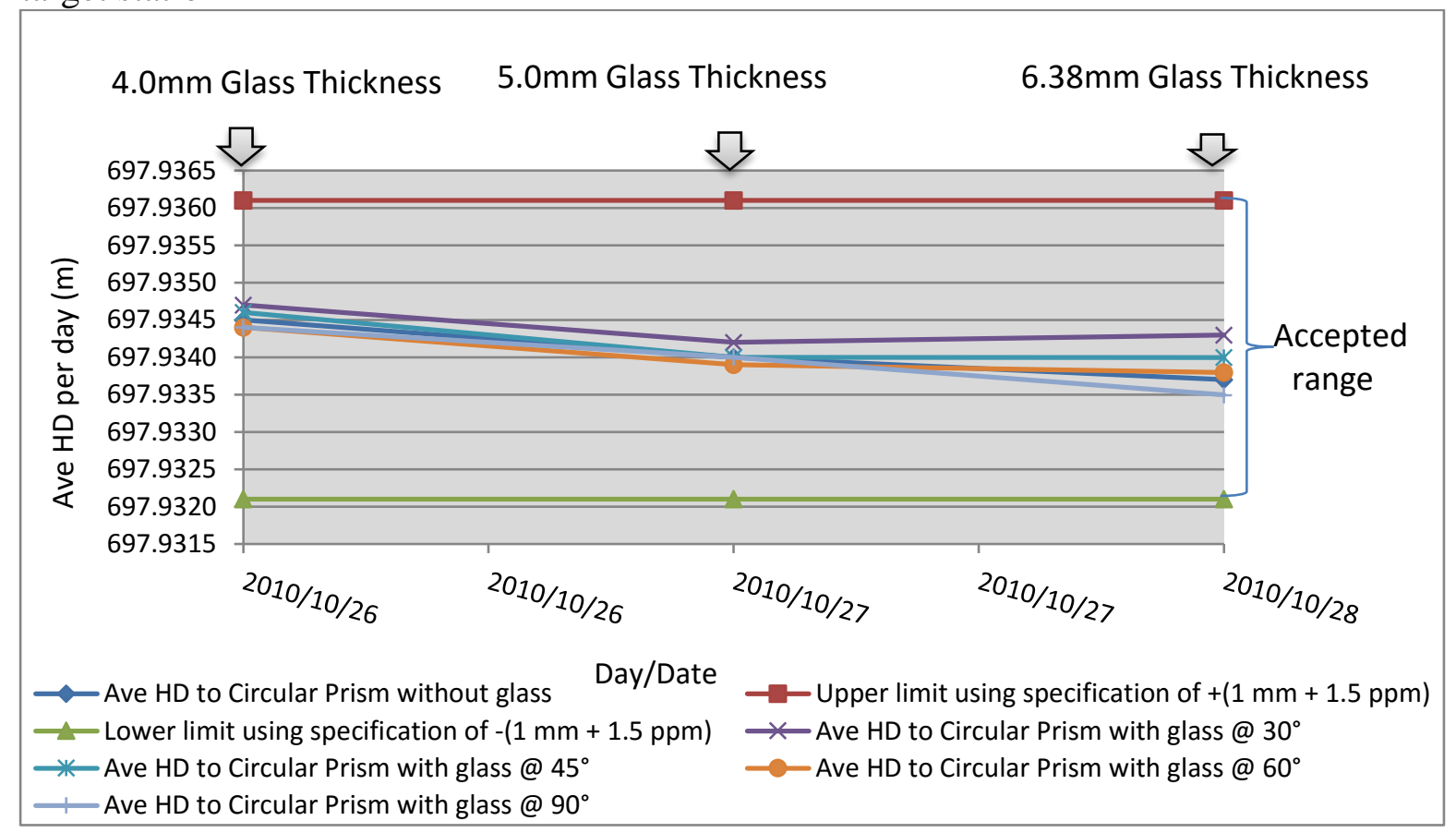

Figure 6: Average HDs to circular prism corrected for prism constant, scale factor, atmospheric and glass thickness, as seen in the second target station 
The impact when monitoring the Leica circular prism, as shown in Figure 5, ranged between $1.8 \mathrm{~mm}$ and $2.1 \mathrm{~mm}$ when $4.0 \mathrm{~mm}$ glass was used. It ranged between $2.6 \mathrm{~mm}$ and $2.9 \mathrm{~mm}$ when $5.0 \mathrm{~mm}$ glass was used, while the impact caused by $6.38 \mathrm{~mm}$ glass ranged between $3.6 \mathrm{~mm}$ and $4.4 \mathrm{~mm}$. The impact also changed after applying the glass-thickness correction formula, as shown in Figure 6. The impact range caused by a $4.0 \mathrm{~mm}$ glass thickness reduced to $-0.1 \mathrm{~mm}$ and $0.2 \mathrm{~mm}$. A $5.0 \mathrm{~mm}$ glass impact changed to $-0.1 \mathrm{~mm}$ and $0.2 \mathrm{~mm}$, while a $6.38 \mathrm{~mm}$ glass impact changed to $-0.2 \mathrm{~mm}$ and $0.6 \mathrm{~mm}$.

\subsection{Results and Discussions for Glass Colour (Glass Tint Level).}

The result of the data analysis when monitoring the Leica circular prism at the first target position during the glass-colour model test is presented in Figure 7. The graph shows the average daily HD measurements corrected for prism constant, scale factor and atmospheric corrections, but not corrected for glass impact. The result after all corrections, including prism constant, scale factor, atmospheric and glass corrections, is presented in Figure 8 .

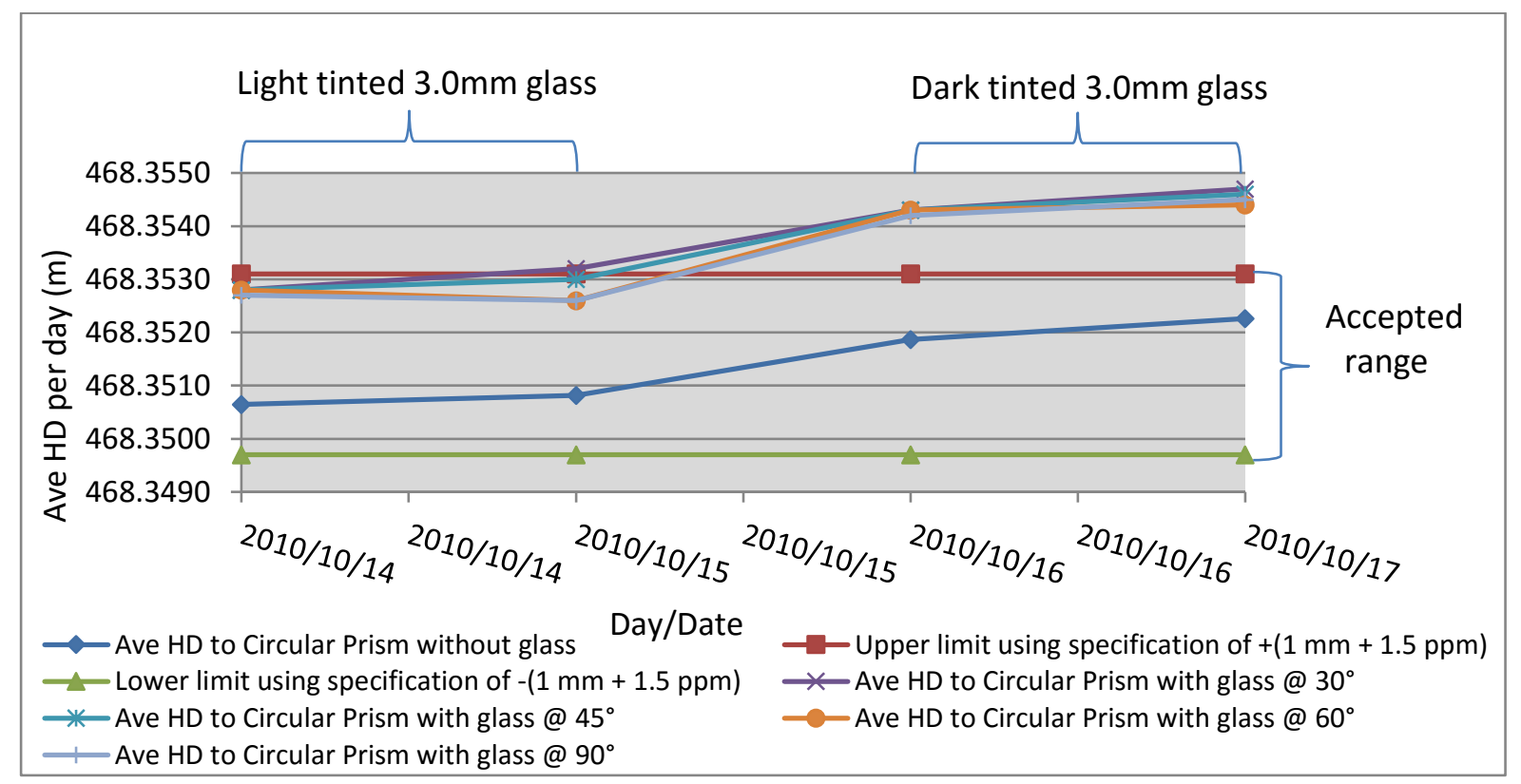

Figure 7: Average HDs to circular prism corrected for prism constant, scale factor and atmospheric corrections, but not corrected for glass thickness impact, as seen in the first target station 


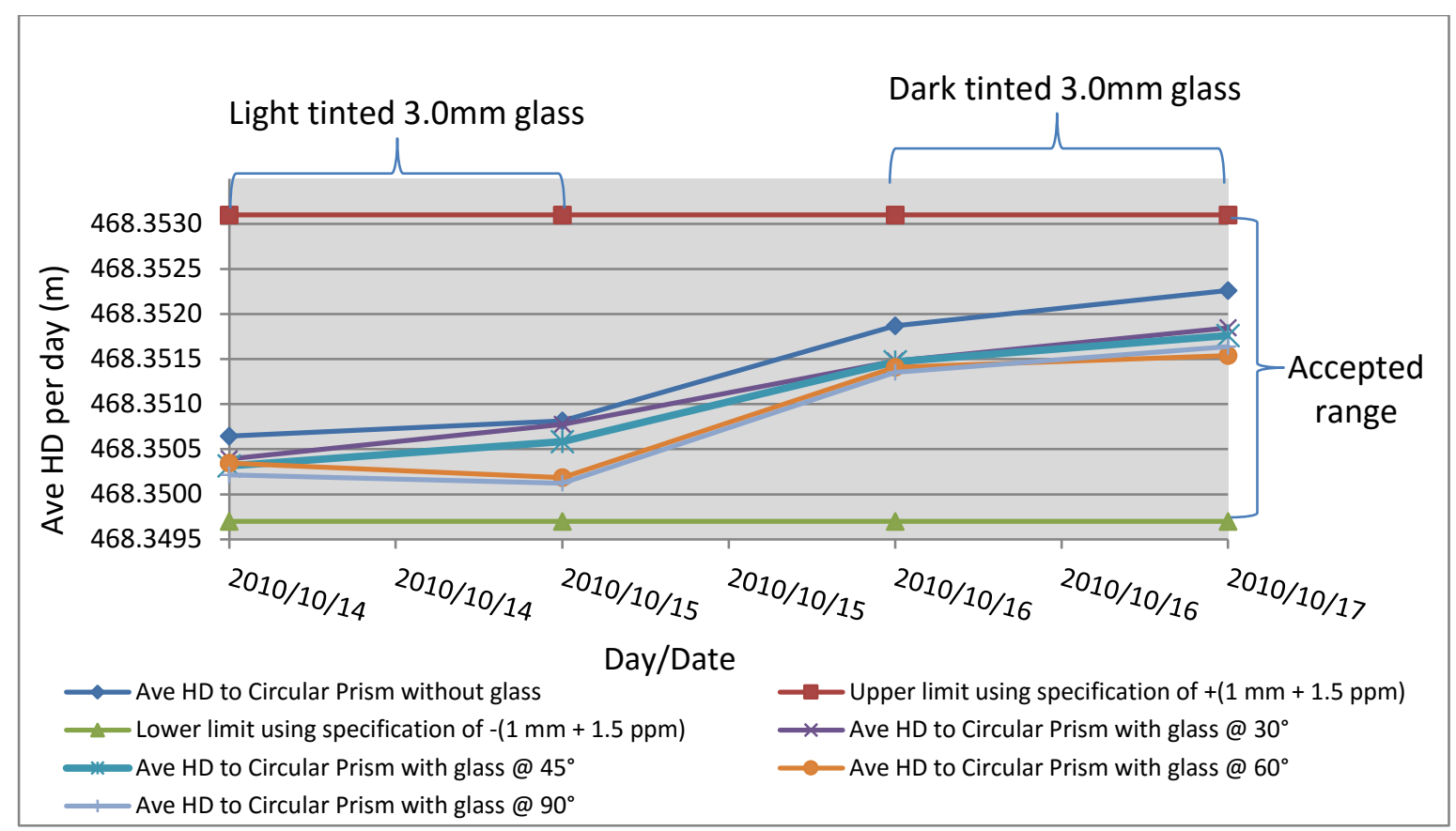

Figure 8: Average HDs to circular prism corrected for prism constant, scale factor, atmospheric and glass thickness, as seen in the first target station

Figure 7 shows the average daily HD measurements to the circular prisms during the glass colour test. In the graph only HD readings without glass fall within the accuracy limits, while all the other HD readings with 5\% (light-tinted) and 50\% (dark-tinted) tinted glass are outside the accuracy limits. The impact increases with increase in glass tint level. In Figure 7, the impact ranged between $1.8 \mathrm{~mm}$ and $2.4 \mathrm{~mm}$ when light-tinted glass was used. It also ranged between $2.1 \mathrm{~mm}$ and $2.4 \mathrm{~mm}$ when dark-tinted glass was used. In addition, the situation changed after applying the glass-colour impact correction formula, as shown in Figure 8. The impact caused by $3.0 \mathrm{~mm}$ light-tinted glass was reduced to $-0.7 \mathrm{~mm}$ and $0.0 \mathrm{~mm}$, while the dark-tinted $3.0 \mathrm{~mm}$ glass impact changed to $-0.7 \mathrm{~mm}$ and $-0.4 \mathrm{~mm}$ after applying the glasscolour impact correction formula to the HD readings.

At the second target station, only HD readings with and without light-tinted glass could be measured. The total station consistently signalled Error 256, meaning that the EDM measurement was not achieved due to detection of multiple targets, targets moving, a break in the beam or air turbulence, when measurements were taken through dark-tinted glass. Therefore, only HDs with and without light-tinted glass were analysed. The results when monitoring the Leica circular prism at the second target station during the glass-colour model test are shown in Figures 9 and 10. 


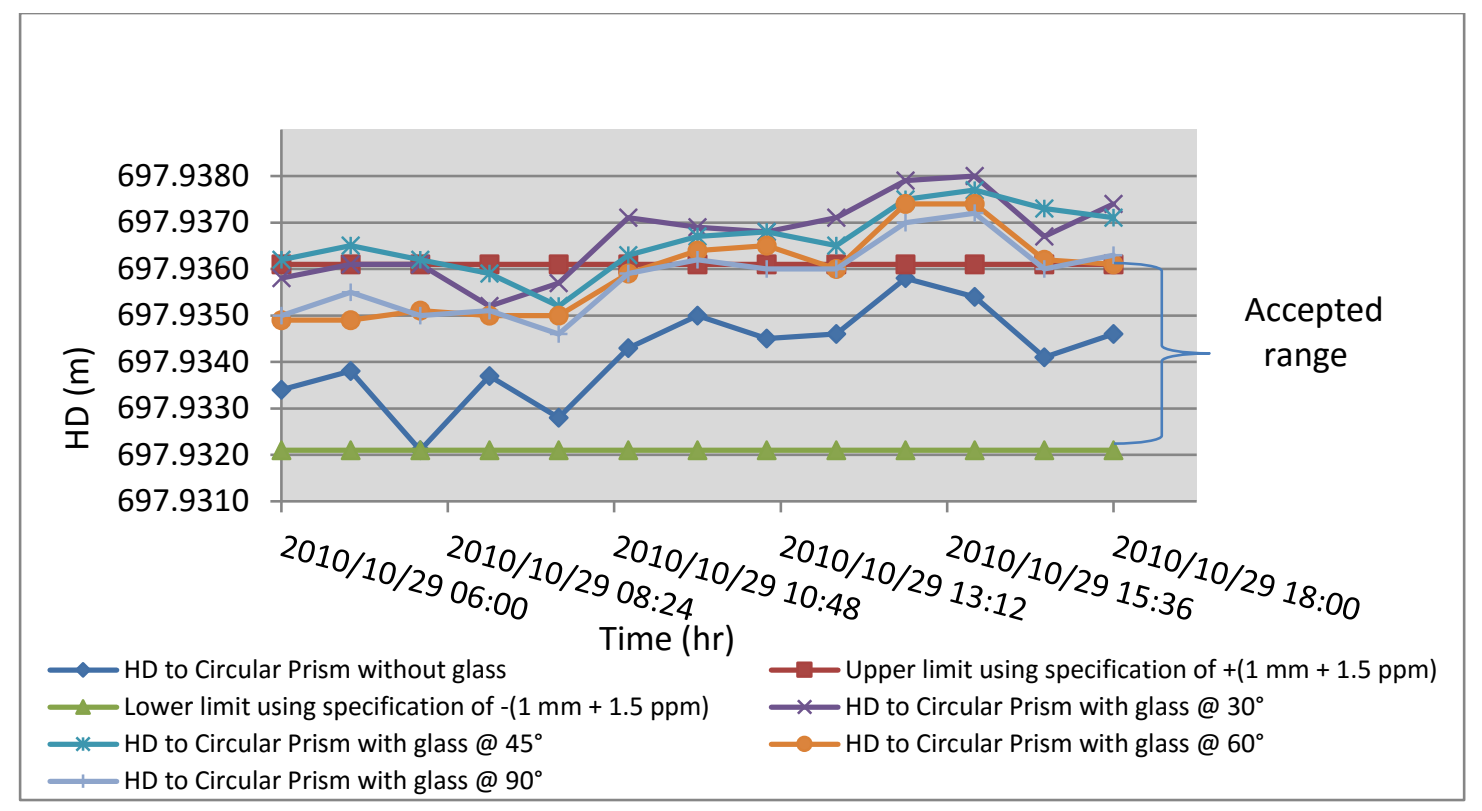

Figure 9: HDs to circular prism after prism constant, scale factor and atmospheric corrections, but before glass colour correction using light tinted $3.0 \mathrm{~mm}$ glass, as seen in the second target station

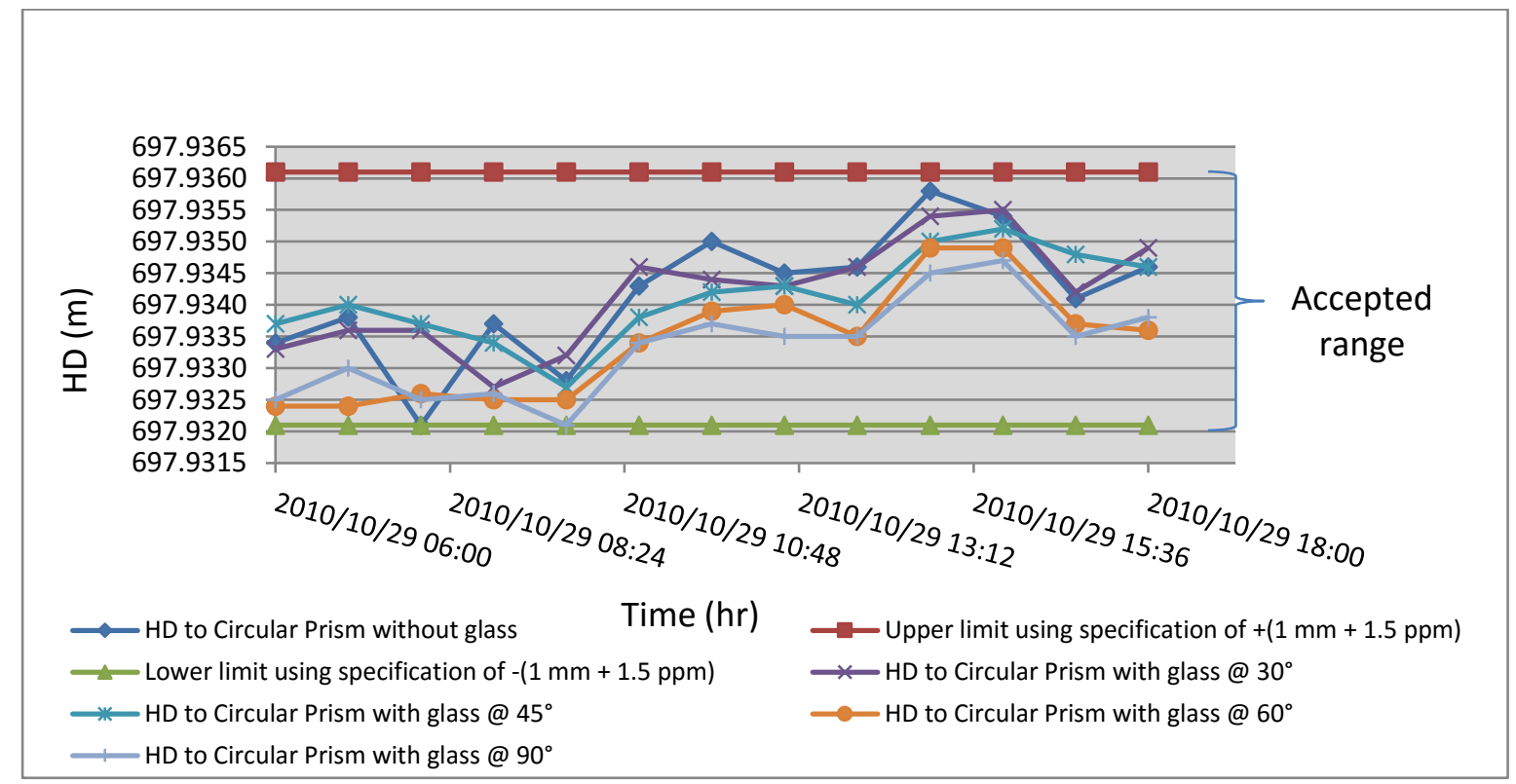

Figure 10: HDs to circular prism after prism constant scale factor, atmospheric and glass colour corrections using light tinted $3.0 \mathrm{~mm}$ glass, as seen in the second target station Figure 9 reveals that only HD readings without glass are within the accuracy limits. All the other HDs measured when there was light-tinted glass in place are outside the accuracy limits. The impact caused by the light-tinted glass ranges between $1.2 \mathrm{~mm}$ and $4.0 \mathrm{~mm}$, as evident in Figure 9. The impact also reduced to $-1.1 \mathrm{~mm}$ and $1.6 \mathrm{~mm}$ after applying the glassthickness correction formula, as shown in Figure 10. 


\section{Conclusion and Recommendation}

The paper discussed total station survey monitoring and its associated errors. The graphs generated during the data analysis clearly reveal that the TCR 1201 total station used for this research is good for monitoring, since all the HDs measured without glass fell within the accuracy limits specified by the instrument manufacturer. However, distance measurement through glass has an impact on the performance of the total station and must therefore be catered for. The paper also discussed the steps taken to model the systematic error caused by the glass medium. The models generated performed well in reducing this error and ensured that all distances measured through the glass medium fall within the accuracy limits specified by the instrument manufacturer. However, there is a need for further research with regard to the colour aspect of the glass. The glass-colour impact model reveals that the angular positions of the glass have more of an impact on the HD readings when tinted glass panes were used, as opposed to the use of non-tinted glass.

\section{Acknowledgement}

This paper is part of research project 3.9, financed by Coaltech Research Association, South Africa and the University of the Witwatersrand Johannesburg. The authors are grateful to both sponsors.

\section{References}

Afeni, T.B. and Cawood, F.T., 2012. "Do the properties of glass matter when taking total station distance measurements through an observation window? Journal of the Institute of Mine Surveyor of South Africa, Vol. XXXVI, No. 2, pp $21-28$.

Afeni, T.B. and Cawood, F.T. 2010. "Pre-delivery Calibration on a new Total Station Geosystems Africa Laboratory Experience”. Journal of the Institute of Mine Surveyor of South Africa. Vol. XXXIV, No. 2, pp. $8-19$.

Bannister, A., Raymond, S. And Baker, R. (1998): Surveying. Pearson Education Ltd. Edinburgh Gate, England.502pp.

Burnside, C.D., 1991. "Electromagnetic Distance Measurement”. BSP Professional Books, Great Britain; $3^{\text {rd }}$ Edition, 278pages. 
Duffy, M.A., Hill, C., Whitaker, C., Chrzanowski, A., Lutes, J. And Bastin, G. 2001. “An Automated and Integrated Monitoring Scheme for Diamond Valley Lake in California”. Proc. of the 10th FIG Symposium on Deformation Measurements, 19-22 March, Orange, California, USA; 21pp.

Hill, C.D. and Sippel, K.D. 2002. "Modern, Deformation Monitoring: A Multi Sensor pproach”. FIG XXII International Congress, Washington GC, USA; 12pp.

Kuhlmann, H. and Glaser, A. (2002): "Investigation of New Measurement Techniques for Bridge Monitoring." 2nd Symposium on Geodesy for Geotechnical and Structural Engineering, Berlin, Germany.

Lange, C and Kippelen, D., 2008. "Real-Time Monitoring for Support of Excavation". GoeStrata, Geo-institute of ASCE (American Society of Civil Engineers), vol. 9, no. 1, pp. $16-18$.

Leung, K. 2001. “Automatic Real-time Monitoring System (ARMS) - A Robotic Solution to Slope Monitoring". Proc. of the 10th FIG Symposium on Deformation Measurements, 19-22 March, Orange, California, USA, pp 313-318.

Lutes, J.A. (2002). “Automated dam displacement monitoring using a robotic total station”. Master of Science dissertation, University of New Brunswick, Fredericton, Canada.

Ostdiek, V.J. and Bord, D.J. (2008): Inquiry into Physics. $6^{\text {th }}$ edition, Thomson Learning Academic Resources Center, 10, Drive, Belmont, CA, USA.

Palazzo, D., Friedmann, R., Nadal, C., Santos-Filho, M., Veiga, L., and Faggion, P. 2006. "Dynamic Monitoring of Structures using a Robotic Total Station". XXIII FIG Congress, Munich, Germany, Oct. 8-13, 2006; 10pp.

Radovanovic, R. S. and Teskey, W. F., 2001. "Dynamic Monitoring of Deforming Structures: GPS verses Robotic Tacheometry Systems." The 10th FIG International Symposium on Deformation Measurements, Orange, California, USA, 10pp.

Rencher, A.C. and Schaalje, G.B. (2007): Linear Models in Statistics. John Wiley \& Sons Inc., Hoboken, New Jersey. 672pp.

Taylor, J.R., 1999. An Introduction to Error Analysis: The Study of Uncertainties in Physical Measurements. University Science Books, 323pp.

Wyllie, D.C. and Mah, C.W. (2004): Rock Slope Engineering Civil and Mining. Spon Press, Taylor and Francis e-library; 456pp.

Zahariadis, H. And Tsakiri, M., 2006. "Low Cost Monitoring System in the Open Pit Lignite Mines of Megalopoli, Greece". $3^{\text {rd }}$ IAG/12 ${ }^{\text {th }}$ FIG Symposium, Baden; 10pp. 


\section{Appendix A}

\section{The effect of glass on beam of light}

The effect of the shelter glass on the beam generated by the total station during monitoring with RTS from transfer beacon shelter is called refractive effects and it is based on Snell's law. This law expresses the relationship between the angles of incidence and refraction, when a light ray passes through a boundary between two different isotropic media, namely air and glass, as in regards to this study. Ostdiek and Bord (2008) simplified the whole process by saying, "a light ray is bent toward the normal when it enters a transparent medium (e.g. glass or water) in which light travels more slowly. It is bent away from the normal when it enters a medium in which light travels faster". Based on Snell's theory, the beam from the RTS passes through the air inside the total station shelter (transfer beacon shelter) and strikes the shelter glass window at an angle of incidence $\theta$ ' with respect to the surface normal. It refracts and passes through the glass at angle $\theta_{\mathrm{g}}$ with respect to the surface normal. The beam is slowed down when passing through the glass, because the refractive index of the glass $n_{g}$ is greater than the refractive index of the air $n_{a}$. When the beam emerges from the glass, it refracts once more so that its angle with respect to the surface normal is again $\theta$ and also resumes its original speed. Figure A.1 below demonstrates the whole scenario.

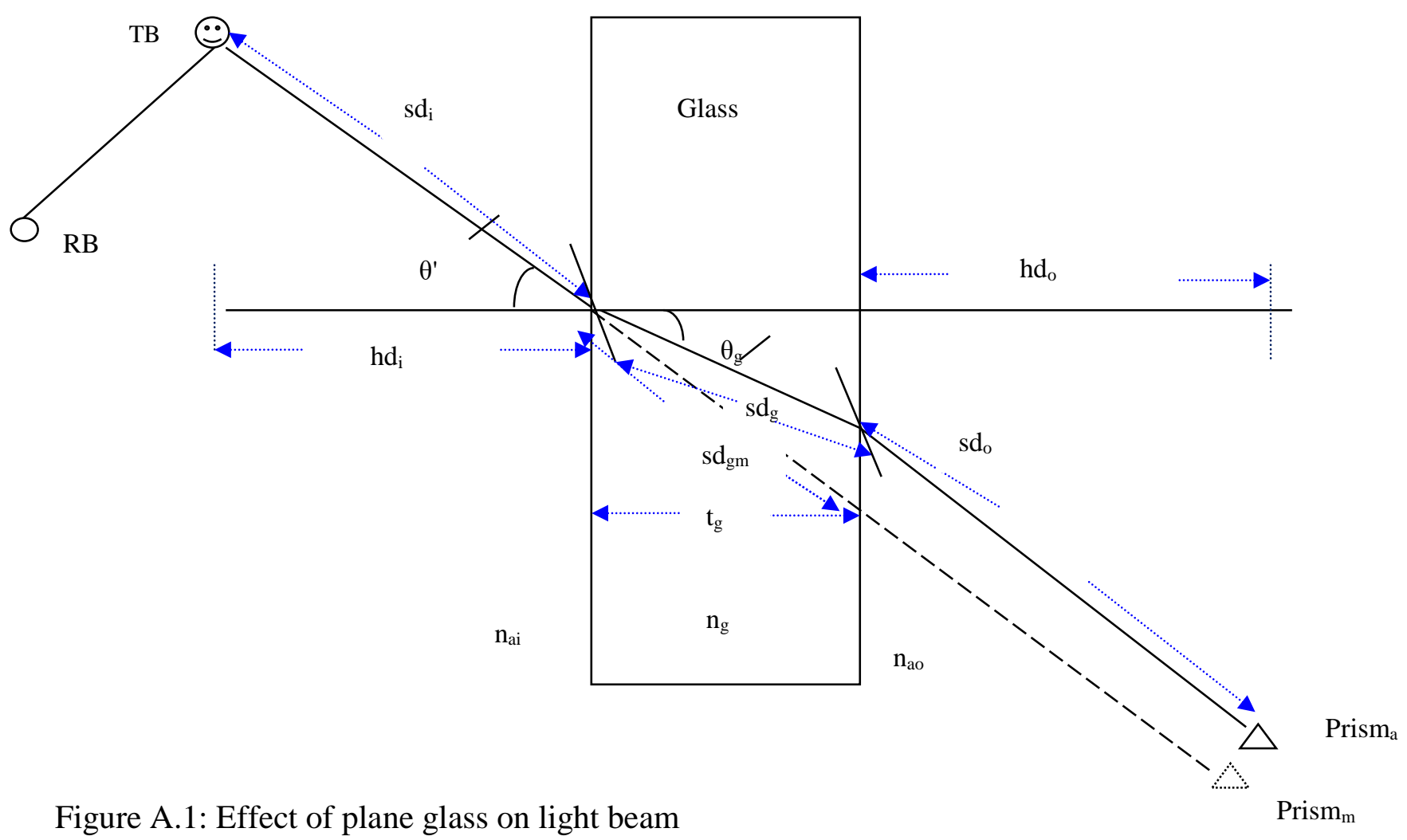


where:

TB is the transfer beacon upon which the RTS is mounted inside the shelter;

$\mathrm{RB}$ is the reference beacon (control point) for orientation;

$\theta^{\prime}$ is the angle of incidence of the RTS with respect to the surface normal of the glass;

$\mathrm{sd}_{\mathrm{i}}$ is the slope distance between the RTS and the glass;

hd $_{\mathrm{i}}$ is the horizontal distance between the RTS and the glass;

$\mathrm{n}_{\mathrm{ai}}$ is the refractive index of air inside the shelter;

$\theta_{\mathrm{g}}$ is the angle of refraction within the glass;

$\mathrm{sd}_{\mathrm{g}}$ is the slope distance within the glass or distance travelled by the RTS beam

through the glass;

$\mathrm{sd}_{\mathrm{gm}}$ is the slope distance that would be measured by the RTS through the glass;

$\operatorname{tg}_{\mathrm{g}}$ is the thickness of the glass;

$\mathrm{n}_{\mathrm{g}}$ is the refractive index of the glass;

$\mathrm{n}_{\mathrm{ao}}$ is the refractive index of air outside the shelter;

$\mathrm{sd}_{\mathrm{o}}$ is the slope distance between the glass and the target, the prism, that is being monitored, while $\mathrm{hd}_{\mathrm{o}}$ is the corresponding horizontal distance; and

Prism $_{m}$ is the measured prism position, while Prism $\mathrm{a}_{\mathrm{a}}$ is the actual prism position.

Mathematically, the total slope distance would be:

$$
\mathrm{sd}_{\mathrm{total}}=\mathrm{sd}_{\mathrm{i}}+\mathrm{sd}_{\mathrm{g}}+\mathrm{sd}_{\mathrm{o}}
$$

(where $s d_{g}=\frac{t_{g}}{\cos \left(\theta_{g}\right)} ;$ and $\theta_{g}=\sin ^{-1}\left[\sin (\theta) \times \frac{n_{a}}{n_{g}}\right]$ )

While horizontal distance would be:

$$
\mathrm{hd}_{\text {total }}=\mathrm{hd}_{\mathrm{i}}+\mathrm{t}_{\mathrm{g}}+\mathrm{hd}_{\mathrm{o}}
$$

Consequently, the actual coordinate of the prism would be:

$$
\begin{aligned}
& \operatorname{Prism}_{\mathrm{a}}\left(\mathrm{Y}_{\mathrm{a}}\right)=\left(\mathrm{sd}_{\mathrm{i}}+\mathrm{sd}_{\mathrm{o}}\right) \cdot \sin (\theta)+\mathrm{sd}_{\mathrm{g}} \cdot \sin \left(\theta_{\mathrm{g}}\right) \text {; and } \operatorname{Prism}_{\mathrm{a}}\left(\mathrm{X}_{\mathrm{a}}\right)=\left(\mathrm{sd}_{\mathrm{i}}+\mathrm{sd}_{\mathrm{o}}\right) \cdot \cos (\theta)+ \\
& \operatorname{sdg}_{\mathrm{g}} \cdot \cos \left(\theta_{\mathrm{g}}\right) \text {..... }
\end{aligned}
$$

However, all the above quantities are hardly taken into account, nor are their values known when computing the position of the prism relative to the RTS position. The measured coordinate values that are displayed on the RTS screen are usually computed from:

$$
\begin{aligned}
& \operatorname{Prism}_{m}\left(Y_{m}\right)=\left(\operatorname{sd}_{i}+s d_{g m}+s d_{o}\right) \cdot \sin (\theta) ; \text { and } \operatorname{Prism}_{m}\left(X_{m}\right)=\left(s d_{i}+s d_{g m}+s d_{o}\right) \cdot \cos (\theta) \\
& \text { I.e. } \operatorname{Prism}_{m}\left(Y_{m}\right)=s d_{\text {total. }} \sin (\theta) \text { and } \operatorname{Prism}_{m}\left(X_{m}\right)=\operatorname{sd}_{\text {total }} \cdot \cos (\theta)
\end{aligned}
$$

(where $s d_{g m}=s d_{g} \times \frac{n_{g}}{n_{a o}}$ ) 
If the join between the $\mathrm{TB}$ and $\mathrm{RB}$ is calculated, and the direction from $\mathrm{TB}$ to the prism is known by using RB for orientation, for instance $\alpha_{\mathrm{tb}-\mathrm{p}}$, the above equation $\mathrm{A} 4$, can be rewritten as:

$$
\begin{aligned}
& \operatorname{Prism}_{\mathrm{m}}\left(\mathrm{Y}_{\mathrm{m}}\right)=\left[\left(\mathrm{hd}_{\mathrm{i}}+\mathrm{t}+\mathrm{hd}_{\mathrm{o}}\right) \cdot \sin \left(\alpha_{\mathrm{tb}-\mathrm{p}}\right)\right]+\mathrm{Y}_{\mathrm{TB}} \text {; and } \operatorname{Prism}_{\mathrm{m}}\left(\mathrm{X}_{\mathrm{m}}\right)=\left[\left(\mathrm{hd}_{\mathrm{i}}+\mathrm{t}_{\mathrm{g}}+\right.\right. \\
& \text { hd } \left.\left._{\mathrm{o}}\right) \cdot \cos \left(\alpha_{\mathrm{tb}-\mathrm{p}}\right)\right]+\mathrm{X}_{\mathrm{TB}} \\
& \text { i.e. } \left.\operatorname{Prism}_{\mathrm{m}}\left(\mathrm{Y}_{\mathrm{m}}\right)=\left[\mathrm{hd}_{\mathrm{total}} \cdot \sin \left(\alpha_{\mathrm{ts}-\mathrm{p}}\right)\right]+\mathrm{Y}_{\mathrm{TB}}\right] \text {; and } \operatorname{Prism}_{\mathrm{m}}\left(\mathrm{X}_{\mathrm{m}}\right)=\left[\mathrm{hd}_{\mathrm{total} \cdot \cos }\left(\alpha_{\mathrm{tb}-\mathrm{p}}\right)\right]+ \\
& \mathrm{X}_{\mathrm{TB}} \text {. }
\end{aligned}
$$

where:

$\alpha_{\mathrm{tb}-\mathrm{p}}$ is the direction of prism from the instrument station TB; and

$\mathrm{Y}_{\mathrm{TB}}$ and $\mathrm{X}_{\mathrm{TB}}$ are the coordinates of instrument station TB or the transfer beacon.

The displayed coordinate on the screen of the RTS are based on equations A4 and A5. According to Lutes (2002), this is based on the assumptions that:
a. the glass is perfectly flat on both sides;
b. the inside and outside surfaces of the glass are parallel;
c. the glass molecules are pure, i.e. without bubbles in the inner structure of the glass;
d. the glass refractive index is uniform;
e. the refractive index of air inside the shelter is identical to that outside of the shelter; and
f. the refractive index of the air is uniform.

Practically, the above assumptions are not attainable. Therefore, there is a need to examine the effect of the shelter glass on the quality of distances measured with a total station setup in a transfer beacon shelter. 


\section{Computation of Refractive Effects on Distance Measurements}

During distance measurement to the short monitoring target, the following were recorded:

$\mathrm{t}_{\mathrm{g}}=3.0 \mathrm{~mm} \quad$ Thickness of the glass

$\theta^{\prime}=60^{\circ} \quad$ Angle of incidence of total station beam with shelter glass

$\mathrm{n}_{\mathrm{ao}}=1.00028 \quad$ Refractive index of air (see Table 2.6 in chapter two)

$\mathrm{n}_{\mathrm{g}}=1.52 \quad$ Refractive index of shelter glass (see sub-section 4.2.5 in chapter four)

\section{The angle of refraction of the total station beam}

Using equation $\mathrm{A} 1$ in chapter two:

$\mathrm{sd}_{\mathrm{total}}=\mathrm{sd}_{\mathrm{i}}+\mathrm{sd}_{\mathrm{g}}+\mathrm{sd}_{\mathrm{o}}$

(where $s d_{g}=\frac{t_{g}}{\cos \left(\theta_{g}\right)}$; and $\theta_{g}=\sin ^{-1}\left[\sin (\theta) \times \frac{n_{a}}{n_{g}}\right]$ )

$\theta_{\mathrm{g}}$ is the angle of refraction within the glass;

$\mathrm{sd}_{\mathrm{g}}$ is the actual distance within the glass that the beam is supposed to travel

$\theta_{g}=\sin ^{-1}\left[\sin 60 \times \frac{1.00028}{1.52}\right]=34.7^{\circ}$

$s d_{g}=\frac{3}{\cos 34.7}=3.65 \mathrm{~mm}$

The measured distance within the glass by the total station is $\mathrm{sd}_{\mathrm{gm}}$ (see equation $\mathrm{A} 4$ above):

$\operatorname{Prism}_{\mathrm{m}}\left(\mathrm{Y}_{\mathrm{m}}\right)=\left(\mathrm{sd}_{\mathrm{i}}+\mathrm{sd}_{\mathrm{gm}}+\mathrm{sdo}\right) \cdot \sin (\theta) ; \operatorname{Prism}_{\mathrm{m}}\left(\mathrm{X}_{\mathrm{m}}\right)=\left(\mathrm{sd}_{\mathrm{i}}+\mathrm{sd}_{\mathrm{gm}}+\mathrm{sdo}\right) \cdot \cos (\theta) ;$

(where: $\left.s d_{g m}=s d_{g} \times \frac{n_{g}}{n_{a o}}\right)=3.65 \times \frac{1.52}{1.00028}=5.546 \mathrm{~mm}$ 
The difference between the actual distance $\mathrm{sd}_{\mathrm{g}}$ that the RTS is supposed to measure and the measured distance $\operatorname{sd}_{\mathrm{gm}}$ is the refractive effect caused by the glass material.

Refractive effect of $3.0 \mathrm{~mm}$ glass $=5.546-3.65=1.89 \mathrm{~mm}$

Using the same procedures, the $\operatorname{sd}_{\mathrm{g}}$ for $4.0 \mathrm{~mm}, 5.0 \mathrm{~mm}$ and $6.38 \mathrm{~mm}$ would be: $4.868 \mathrm{~mm}$, $6.085 \mathrm{~mm}$ and $7.764 \mathrm{~mm}$, while the corresponding $\mathrm{sd}_{\mathrm{gm}}$ would be: $7.3967 \mathrm{~mm}, 9.246 \mathrm{~mm}$ and $11.798 \mathrm{~mm}$.

Therefore, their refractive effects would be: $2.51 \mathrm{~mm}, 3.2 \mathrm{~mm}$ and $4.03 \mathrm{~mm}$.

These can be summarised in the Table below:

Difference between the physical model and the regression model results

\begin{tabular}{||l|l|l|l|}
\hline Glass thickness & Physical model $(\mathrm{mm})$ & Regression model $(\mathrm{mm})$ & Difference $(\mathrm{mm})$ \\
\hline 3 & 1.89 & 1.70 & 0.19 \\
\hline 4 & 2.51 & 2.40 & 0.11 \\
\hline 5 & 3.20 & 3.10 & 0.10 \\
\hline 6.38 & 4.03 & 4.07 & 0.04 \\
\hline
\end{tabular}

The variation is very small (i.e. less than $0.2 \mathrm{~mm}$ ). This is an indication that the regression model developed is effective despite being a much simpler approach. However, the little variation may be as a result of non-attainability of the assumptions highlighted in Lutes (2002) as stated above. 